Jurnal Agroteknologi, Vol. 6 No. 1, Agustus $2015: 9$ - 16

\title{
PEMANFAATAN BEBERAPA JENIS DAN DOSIS LIMBAH KELAPA SAWIT (Elaeis guinensis Jacq) TERHADAP PERUBAHAN PH, N, P, K TANAH PODSOLIK MERAH KUNING (PMK)
}

\author{
FITRI RAMADHANI ${ }^{1}$, ERVINA ARYANTI ${ }^{2}$, DAN ROBBANA SARAGIH ${ }^{2}$ \\ ${ }^{1}$ Alumni Prodi Agroteknologi Fakultas Pertanian dan Peternakan \\ 2 Dosen Prodi Agroteknologi Fakultas Pertanian dan Peternakan \\ Universitas Islam Negeri Sultan Syarif Kasim Riau \\ Email: hadiderna@yahoo.com
}

\begin{abstract}
This research has been conducted on January until February 2015 at Agrostologi laboratory, industrial feed and soil science laboratory, in State Islamic University Sultan Syarif Kasim Riau. The purposed of the research was to determine the effect of bunch ash, boiler ash, and palm oil sludge with different doses of the red-yellow podsolic fertility. The research used random sampling method that consist of (1). Red-yellow podzolic soil with a bunch ash as much as 5 ton/ha (25 g), 10 ton/ha (50 g), 15 ton/ha (75 g). (2). Red-yellow podzolic soil with boiler ash as much as 5 ton/ha (25 g), 10 ton/ha (75 g), 15 ton/ha (75 g). (3). Red-yellow podzolic soil with sludge as much as 5 ton/ha (25 g), 10 ton/ha (50 g), 15 ton/ha $(75 \mathrm{~g})$. Total of treatment were 20 pollybag. Parameters observation consist of value $\mathrm{pH} \mathrm{H} 2 \mathrm{O}, \mathrm{N}$, $P, K$. The results showed that bunch ash doses of 15 ton/ha was the best material to improvement of soil chemical properties red-yellow podzolic ( $\mathrm{pH} \mathrm{H} 2 \mathrm{O}, \mathrm{P}$ and K), subsequently followed by boiler ash, but a decline $N$ of giving bunch ash and boiler ash while sludge doses 15 ton/ha is the best material to improvement of soil chemical properties $N$.
\end{abstract}

Kata kunci : limbah kelapa sawit, podsolik merah kuning, sifat kimia

\section{PENDAHULUAN}

Tanah merupakan tempat tumbuh dan penyedia unsur hara bagi tanaman. Tanah yang baik dan subur adalah tanah yang mampu menyediakan unsur hara secara cukup dan seimbang untuk dapat diserap oleh tanaman baik unsur makro maupun mikro (Yamani, 2010). Menurut data BPS (2013) luas wilayah Pekanbaru Riau yaitu, 566,56 Ha atau 89,61 persen dan secara astronomis terletak di antara $0^{\circ} 25^{\prime}-0^{\circ} 45^{\prime} \mathrm{LU}$ dan $101^{\circ} 14^{\prime}-101^{\circ} 34^{\prime} \mathrm{BT}$. Pada umumnya Pekanbaru Riau, pada daerah yang tinggi sebagian besar tanahnya berjenis Podzolik Merah Kuning (PMK) sedangkan di daerah yang lebih rendah berjenis tanah gambut.

Dari jenis tanah gambut maupun PMK memiliki karakteristik kimia tanah yang berbeda. Tanah mineral PMK adalah jenis tanah yang terbentuk oleh proses pedogenesis yang menyerupai pembentukan tanah podsol (Indrihastuti, 2004). Tanah mineral PMK memiliki ketebalan material organik tanah $<60$ $\mathrm{cm}$ dan masih sebagian mengalami dekomposisi sehingga masih banyak mengandung serat sehingga agroekosistem pada tanah ini akan menuai banyak kendala terutama pada wilayah kering berkelerengan tinggi (Yuliana, 2012).

Kendala yang sering dihadapi pada tanah mineral PMK yaitu : pertama, $\mathrm{pH}$ tanah yang rendah, kelarutan $\mathrm{Al}, \mathrm{Fe}$, dan $\mathrm{Mn}$ yang tinggi, ketersediaan $\mathrm{P}$ dan Mo yang rendah. Kedua, ketersediaan kation-kation basa dan kejenuhan basa yang rendah mengakibatkan tanah bersifat masam dan miskin hara. Ketiga, dominasi mineral liat kaolinit dan oksida-oksida besi dan aluminium yang menyebabkan tanah ini memiliki kapasitas tukar kation yang rendah. Keempat, tingginya kandungan mineral-mineral dan apabila terlarut menyebabkan kejenuhan kation akan bersifat toksik bagi tanaman, serta anion-anion akan mudah terfiksasi menjadi tidak tersedia bagi tanaman. Untuk itu perlu adanya penambahan bahan organik tanah (BOT) untuk mengatasi permasalahan kesuburan tanah mineral dan tujuannya meningkatkan hasil budidaya seperti penambahan limbah kelapa sawit dalam bentuk abu dan limbah padat yang kemungkinan dapat meningkatkan unsur hara pada tanah mineral (Sasli, 2011).

Berdasarkan data Dinas Perkebunan Provinsi Riau (2013) perkembangan luas areal perkebunan kelapa sawit meningkat secara 
tajam dari tahun ke tahun, yakni 966.786 ha. Provinsi Riau memiliki 1.605 pabrik kelapa sawit (BPS, 2013). Banyaknya jumlah pabrik akan menghasilkan limbah dalam jumlah yang besar diantaranya tandan kosong, wet decanter solid, cangkang, serabut, limbah padat, limbah cair dan air kondensat. Limbah yang dihasilkan dari pabrik kelapa sawit (PKS) akan berdampak negatif bagi lingkungan jika tidak dilakukan pencegahan. Salah satu upaya untuk mengatasi pencemaran dan kerusakan lingkungan maka dilakukan pengolahan limbah kelapa sawit, karena limbah kelapa sawit ini dapat dimanfaatkan sebagai sumber unsur hara (DEPTAN, 2006). Tim PT. Salim Indoplantation (2000) menjelaskan beberapa hasil pengolahan limbah kelapa sawit diantaranya abu boiler, abu janjang dan sludge.

Abu boiler, abu janjang dan sludge kelapa sawit memiliki kandungan hara yang dapat meningkatkan kesuburan kimia tanah. Hasil analisis laboratorium menunjukan abu janjang mengandung hara kalium $(\mathrm{K})$ dan natrium $(\mathrm{Na})$ yang cukup tinggi yaitu : $30 \% \mathrm{~K} 2 \mathrm{O}$ dan $26 \% \mathrm{Na2O}$, kandungan unsur hara abu boiler adalah $\mathrm{N} \mathrm{0,72 \% ,} \mathrm{P2O5} \mathrm{0,84 \% ,} \mathrm{K2O}$ 2,07\% dan Mg 0,62\% (Prasetyo, 2009). Menurut Siregar (2007) sludge yang dihasilkan dari pengolahan minyak sawit (PMS) mengandung unsur hara nitrogen, fosfor, kalium, magnesium, dan kalsium yang cukup tinggi sehingga dapat digunakan sebagai pupuk. Sludge mempunyai $\mathrm{pH}$ yang agak masam, mempunyai kandungan $\mathrm{C}$ organik sangat tinggi, KTK sangat tinggi, $\mathrm{N}$ sedang, $\mathrm{P}$ sangat tinggi, dan unsur-unsur mikro termasuk kategori cukup dan dapat dijadikan sebagai bahan pembenah tanah (PPT, 1983).

Panjaitan et al. (2003) membuktikan bahwa pemberian abu janjang, abu boiler (pembakaran cangkang dan serat kelapa sawit) dan sludge (lumpur) kelapa sawit dapat meningkatkan $\mathrm{pH}$ tanah yang berpengaruh nyata terhadap kenaikan kadar kalium dapat dipertukarkan dan dapat meningkatkan kapasitas tukar kation tanah. Menurut Sari (2011) pemberian abu janjang kelapa sawit secara umum meningkatkan $\mathrm{pH}$ tanah dan ketersediaan $\mathrm{Cu}, \mathrm{Zn}$, Fe dan $\mathrm{Mn}$ pada tanah gambut. Pemberian abu janjang kelapa sawit dengan dosis $20 \mathrm{~g}$ per $8 \mathrm{Kg}$ tanah Ultisol yang diinkubasi selama 2 minggu dapat meningkatkan $\mathrm{pH}$ tanah dari $\mathrm{pH}$ 4,32 menjadi pH 5,5 (Hanibal et al., 2001). Rini et al. (2009) menyatakan dengan penambahan abu boiler dapat menaikan $\mathrm{pH}$ tanah serta memperbaiki sifat fisik, kimia dan biologi pada tanah gambut. Abu janjang kelapa sawit dapat meningkatkan kadar serapan kalium dalam tanaman kentang varietas granola dan mampu mensuplai $\mathrm{K}$ dan $\mathrm{Mg}$ dapat dipertukarkan ke dalam tanah (Ginting, 1991). Menurut Siregar (2007) Pemakaian sludge kelapa sawit memberikan pengaruh nyata terhadap tinggi tanaman, diameter batang, jumlah polong, poduksi perplot, produksi perhektar untuk tanaman kacang hijau.

Penulis bertujuan untuk mengetahui pengaruh pemberian dan jenis bahan terbaik pada abu janjang, abu boiler dan sludge kelapa sawit dengan pemberian dosis yang berbeda terhadap kesuburan tanah podsolik merah kuning.

\section{BAHAN DAN METODE}

Penelitian ini dilaksanakan di Laboratorium Agrostologi, Industri Pakan Dan IImu Tanah UIN Suska Riau, sedangkan analisis sifat kimia tanah dilaksanakan di PT Central Plantation Services Provinsi Riau. Penelitian berlangsung selama 2 (dua) bulan, mulai dari persiapan sampai analisis data dan laporan.

Bahan yang digunakan adalah tanah podsolik merah kuning, abu janjang, abu boiler dan sludge. Alat yang digunakan cangkul, polybag, alat tulis, kamera digital, ayakan tanah, terpal, meteran, sekop dan alat-alat analisis laboratorium yang mendukung penelitian ini.

Penelitian ini mengunakan metode (Random sampling). Data yang diambil diperoleh dari beberapa perlakuan dilapangan kemudian dilakukan analisa untuk mendapatkan data kuantitatif. Analisis sampel tanah yang dilakukan merupakan hasil komposit dari tanah PMK dengan abu janjang, abu boiler dan sluge yang terdiri (1). Tanah podsolik merah kuning dengan abu janjang sebanyak 5 ton/ha (25 g), 10 ton/ha $(50 \mathrm{~g}), 15$ ton/ha (75 g). (2). Tanah podsolik merah kuning dengan abu boiler sebanyak 5 ton/ha ( $25 \mathrm{~g}), 10$ ton/ha (50 g), 15 ton/ha (75 g). (3). Tanah podsolik merah kuning dengan sludge sebanyak 5 ton/ha $(25 \mathrm{~g}), 10$ ton/ha $(50 \mathrm{~g}), 15$ ton/ha $(75 \mathrm{~g})$. Tiap perlakuan terdapat 2 polybag, dengan demikian terdapat 20 polybag.

Pelaksanaan penelitian melalui dua tahap, tahap pertama tanah podsolik merah kuning dibersihkan dari kotoran yang ada selanjutnya dikeringudarakan dan dilakukan 
pengayakan dan limbah kelapa sawit sludge sebelum dipakai terlebih dahulu dikeringudarakan karena kondisinya lembab sedangkan abu janjang dan boiler langsung dapat digunakan karena dalam kondisi kering, selanjutnya tanah PMK diambil sebanyak $100 \mathrm{~g}$ kemudian dioven dengan tujuan untuk mendapatkan kadar air. Selanjutnya tanah diambil sebanyak $10 \mathrm{~kg}$ atau $9,763 \mathrm{~kg}$ setara dengan berat kering mutlak dan memasukkannya ke dalam masing-masing polybag, penghitungannya dengan rumus $=(\%$ kadar air tanah $\mathrm{x}$ berat setara kering mutlak) + berat setara kering mutlak yaitu $(2,43 \% \times 9,763$ $\mathrm{kg}+9,763 \mathrm{~kg}=10 \mathrm{~kg}$ )

Tahap selanjutnya adalah pemberian jenis dan dosis limbah kelapa sawit untuk masing-masing perlakuan. Limbah kelapa sawit diberikan di lapisan atas permukaan media (sampai kedalaman $\pm 20 \mathrm{~cm}$ ), dan diaduk merata, selanjutnya diinkubasi selama satu bulan dan disiram dengan air sampai kapasitas lapang kemudian ditutupi dengan terpal lapisan atasnya.

Variabel-variabel pengamatan yang dilakukan adalah $\mathrm{pH} \mathrm{H} 2 \mathrm{O}, \mathrm{N}, \mathrm{P}$ dan $\mathrm{K}$.

\section{HASIL DAN PEMBAHASAN}

\section{Sifat PH H2O, N, P, K Tanah Sebelum Perlakuan}

Hasil analisis kimia tanah sebelum perlakuan ditampilkan pada tabel 4.1. dan dilihat berdasarkan kriteria penilaian hasil analisis sifat kimia tanah BPTP 2005.

Tabel 1. Hasil Analisis PH H2O, N, P, K Tanah PMK Sebelum diberi Perlakuan

\begin{tabular}{lll}
\hline Sifat Kimia & Tanah PMK & Kriteria BPTP 2005 \\
\hline $\mathrm{pH} \mathrm{H} \mathrm{H}_{2} \mathrm{O}$ & 4,80 & Masam \\
$\mathrm{N}-\mathrm{Total}(\%)$ & 0,06 & Sangat rendah \\
$\mathrm{P}_{2} \mathrm{O}{ }_{5}(\mathrm{ppm})$ & 1,07 & Sangat rendah \\
$\mathrm{Kalium}\left(\mathrm{K}_{2} \mathrm{O}\right)$ & 0,21 & Sangat rendah \\
$(\mathrm{mg} / 100 \mathrm{~g})$ & & \\
\hline
\end{tabular}

Sumber: Laboratorium PT Central Plantation Services Riau (2015

Tabel 1 menunjukkan bahwa tanah PMK memiliki $\mathrm{pH} \mathrm{H} 2 \mathrm{O}$ tergolong masam, kandungan N, P, K sangat rendah. Hasil penelitian menunjukkan bahwa tanah PMK adalah tanah yang telah mengalami pelapukan lanjut, dimana proses pencucian telah berlangsung intensif dengan kandungan basabasa dapat tukar yang rendah dan kandungan bahan organik yang rendah (Mahbub, 2011).

\section{Sifat PH H2O, N, P, K Limbah Kelapa Sawit}

Hasil analisis terhadap kandungan kimia limbah kelapa sawit, yaitu abu janjang, abu boiler dan sludge, ditampilkan pada tabel 2 dan dilihat berdasarkan kriteria penilaian hasil analisis sifat kimia tanah BPTP 2005.

Tabel 2. Hasil Analisis $\mathrm{PH} \mathrm{H} 2 \mathrm{O}, \mathrm{N}, \mathrm{P}, \mathrm{K}$ Limbah Kelapa Sawit

\begin{tabular}{llll}
\hline \multirow{2}{*}{ Sifat Kimia } & \multicolumn{4}{l}{ Limbah Kelapa Sawit } \\
\cline { 2 - 4 } & $\begin{array}{l}\text { Abu Janjang } \\
\text { (Kriteria) }\end{array}$ & $\begin{array}{l}\text { Abu Boiler } \\
\text { (Kriteria) }\end{array}$ & $\begin{array}{l}\text { Sludge } \\
\text { (Kriteria) }\end{array}$ \\
\hline pH $\mathrm{H}_{2} \mathrm{O}$ & 12,30 & 9,30 & 5,23 \\
& (Alkalis) & (Alkalis) & (Masam) \\
$\mathrm{N}$-Total (\%) & 3,64 & 1,98 & 1,12 \\
& (Sangat tinggi) & (Sangat tinggi) & (Sangat tinggi) \\
& 1,40 & 0,67 & 0,51 \\
$\mathrm{P}_{2} \mathrm{O}$ (ppm) & $($ Sangat rendah) & (Sangat rendah) & (Sangat rendah) \\
Kalium $\left(\mathrm{K}_{2} \mathrm{O}\right)$ & 30,0 & 4,13 & 2,82 \\
(mg/100g) & (Sedang) & (Sangat rendah) & (Sangat rendah) \\
\hline
\end{tabular}

Sumber: Laboratorium PT Central Plantation Services Riau (2015)

Tabel 2 menunjukkan bahwa abu janjang dan abu boiler memilki $\mathrm{pH}$ yang tergolong alkalis, sedangkan sludge tergolong masam. Kandungan $\mathrm{N}$ untuk ketiga jenis limbah kelapa sawit tergolong sangat tinggi, kandungan $\mathrm{P}$ sangat rendah dan kandungan $\mathrm{K}$ tergolong sedang untuk abu janjang dan sludge tergolong sangat rendah.

Tingginya $\mathrm{pH}$ karena abu janjang dan abu boiler mengalami pembakaran di dalam insenerator di pabrik kelapa sawit sehingga sisa pembakaran menghasilkan basa basa kation dalam jumlah yang besar seperti $\mathrm{Ca++}, \mathrm{Mg++}$, $\mathrm{K}+, \mathrm{Na++}$ dan senyawa tersebut banyak menyumbangkan ion $\mathrm{OH}$ - (Panjaitan et al., 2003). Kandungan sludge tergolong rendah karena sludge berasal dari bak pengendapan yang sering terkena oleh air hujan sehingga menghasilkan kation asam seperti $\mathrm{H}_{+}, \mathrm{Al}_{+++}$ dan senyawa tersebut banyak menyumbangkan ion $\mathrm{H}+$ di dalam sludge (Jenny, 1999). Kandungan $\mathrm{N}$ yang sangat tinggi karena tandan kosong kelapa sawit memiliki kandungan $\mathrm{C} / \mathrm{N}$ yang tinggi yaitu $45-55$. Abu janjang, abu boiler dan sludge berasal dari tandan kosong kelapa sawit. Tandan kosong kelapa sawit memilki kandungan $P$ yang rendah karena $P$ telah diserap oleh biji.

Pada awalnya tanaman menyerap sebagian besar unsur hara $P$ dalam bentuk ortofosfat primer (H2PO4-), sejumlah kecil diserap dalam bentuk ion otofosfat sekunder (H2PO4-2). Pada tanaman muda, kadar P paling tinggi dijumpai pada pusat pertumbuhan. Apabila tanaman sudah memasuki fase generatif (masak), sebagian $\mathrm{P}$ dimobilisasi ke 
biji atau bagian generatif tanaman. Besarnya kandungan $\mathrm{P}$ yang diserap tanaman hingga 90\% (Winarso, 2005). Tingginya $\mathrm{k}$ andungan kalium karena abu janjang dan abu boiler berasal dari proses pembakaran, hasil dari proses pembakaran mengandung kalium yang tinggi. Rendahnya kandungan $\mathrm{K}$ pada sludge rendah diakibatkan rendahnya $\mathrm{pH}$ sludge mengakibatkan ketersediaan $\mathrm{K}$ menjadi menurun (Baharuddin et al., 2009).

\section{Kadar pH H2O Tanah}

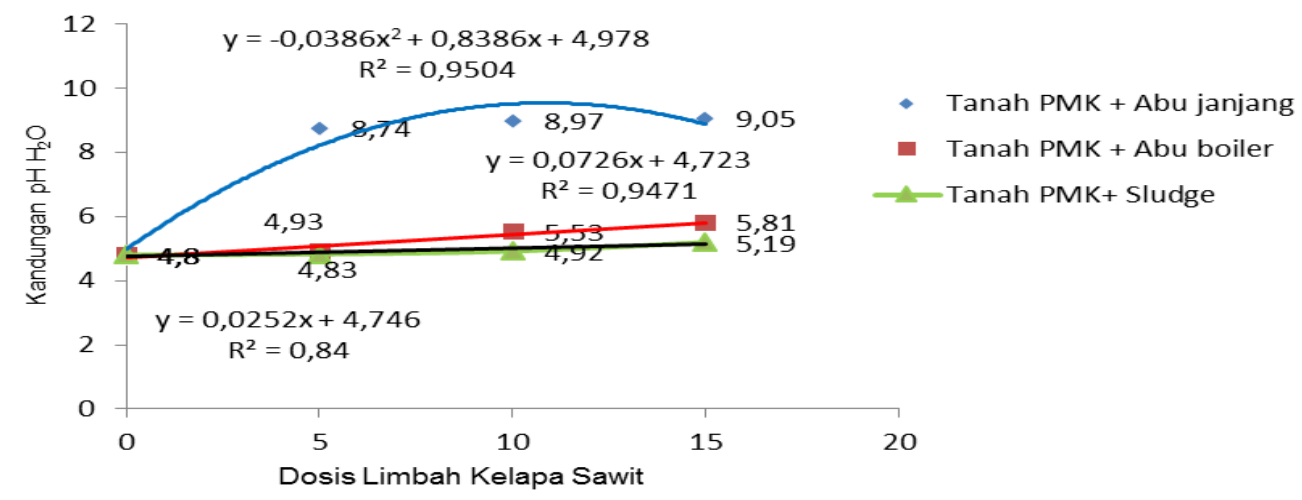

Gambar 1. Grafik respon kandungan $\mathrm{pH} \mathrm{H} 2 \mathrm{O}$ setelah diinkubasi dengan berbagai jenis limbah kelapa sawit

Gambar 1 menunjukkan bahwa peningkatan berbagai dosis limbah kelapa sawit akan memberikan pengaruh terhadap kadar $\mathrm{pH}$ $\mathrm{H} 2 \mathrm{O}$ dengan kurva respon linear positif. Abu janjang, abu boiler dan sludge memiliki nilai koefisien determinasi R2 sebesar 0,950; 0,947 dan 0,84 .

\section{Kadar N Total Tanah}

Terjadi penurunan kadar $\mathrm{N}$ tanah akibat pemberian dari semua jenis abu dan terjadi peningkatan pada sludge kelapa sawit pada
Terjadi kenaikan kadar $\mathrm{pH}$ akibat pemberian dari semua jenis limbah kelapa sawit pada bahan podsolik merah kuning setelah diinkubasi selama satu bulan. Berdasarkan hasil analisis diperoleh kadar $\mathrm{pH}$ tertinggi terdapat pada sampel dengan pemberian abu janjang dosis 15 ton yakni 9,05, sedangkan kadar $\mathrm{pH}$ terendah terdapat pada sampel dengan pemberian sludge dosis 5 ton yakni 4,83. Hubungan antara pemberian berbagai jenis limbah kelapa sawit pada berbagai dosis terhadap kadar $\mathrm{pH}$ bahan podsolik merah kuning dapat dilihat pada gambar 1 . 
Gambar 2 menunjukkan bahwa peningkatan berbagai dosis limbah kelapa sawit berpengaruh terhadap kadar $\mathrm{N}$-total dengan kurva respon linear negatif. Abu janjang, abu boiler dan sludge memiliki nilai koefisien determinasi R2 masing masing sebesar 0,96; 0,966 dan 0,958 .

\section{Kadar P Tanah}

Terjadi peningkatan kadar $\mathrm{P}$ tanah akibat pemberian dari semua jenis limbah kelapa sawit pada bahan podsolik merah kuning setelah diinkubasi selama satu bulan. Berdasarkan hasil analisis diperoleh kadar $\mathrm{P}$ tanah tertinggi terdapat pada sampel dengan pemberian abu janjang dosis 15 ton yakn 38,74 , sedangkan kadar $\mathrm{P}$ terendah terdapat pada sampel dengan pemberian sludge dosis 5 ton yakni 2,51. Hubungan antara pemberian berbagai jenis limbah kelapa sawit pada berbagai dosis terhadap kadar $\mathrm{P}$ bahan podsolik merah kuning dapat dilihat pada gambar 3 .

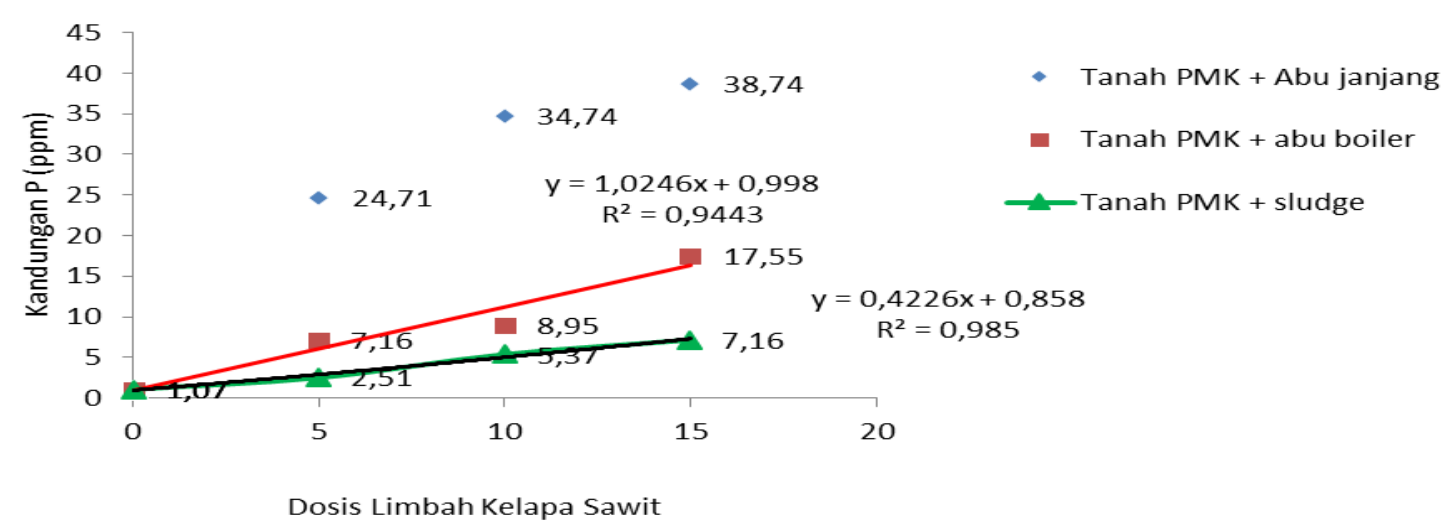

Gambar 3. Grafik respon kandungan hara P2O5 (ppm) setelah diinkubasi dengan berbagai limbah kelapa sawit

Gambar 3 menunjukkan bahwa peningkatan berbagai dosis limbah kelapa sawit memberikan berpengaruh terhadap kadar $P$ dengan kurva respon linear positif. Abu janjang, abu boiler dan sludge memiliki nilai koefisien determinasi R2 masing masing sebesar 0,884 ; 0,944 dan 0,985 .

\section{Kadar K Tanah}

Terjadi peningkatan kadar $\mathrm{K}$ tanah akibat pemberian dari semua jenis limbah kelapa sawit pada bahan podsolik merah kuning setelah diinkubasi selama satu bulan. Berdasarkan hasil analisis diperoleh kadar $\mathrm{K}$ tanah tertinggi terdapat pada sampel dengan pemberian abu janjang dosis 15 ton yakn 3,20 sedangkan kadar $\mathrm{K}$ terendah terdapat pada sampel dengan pemberian sludge dosis 5 ton yakni 0,23 . Hubungan antara pemberian berbagai jenis limbah kelapa sawit pada berbagai dosis terhadap kadar $\mathrm{K}$ bahan podsolik merah kuning dapat dilihat pada gambar 4.

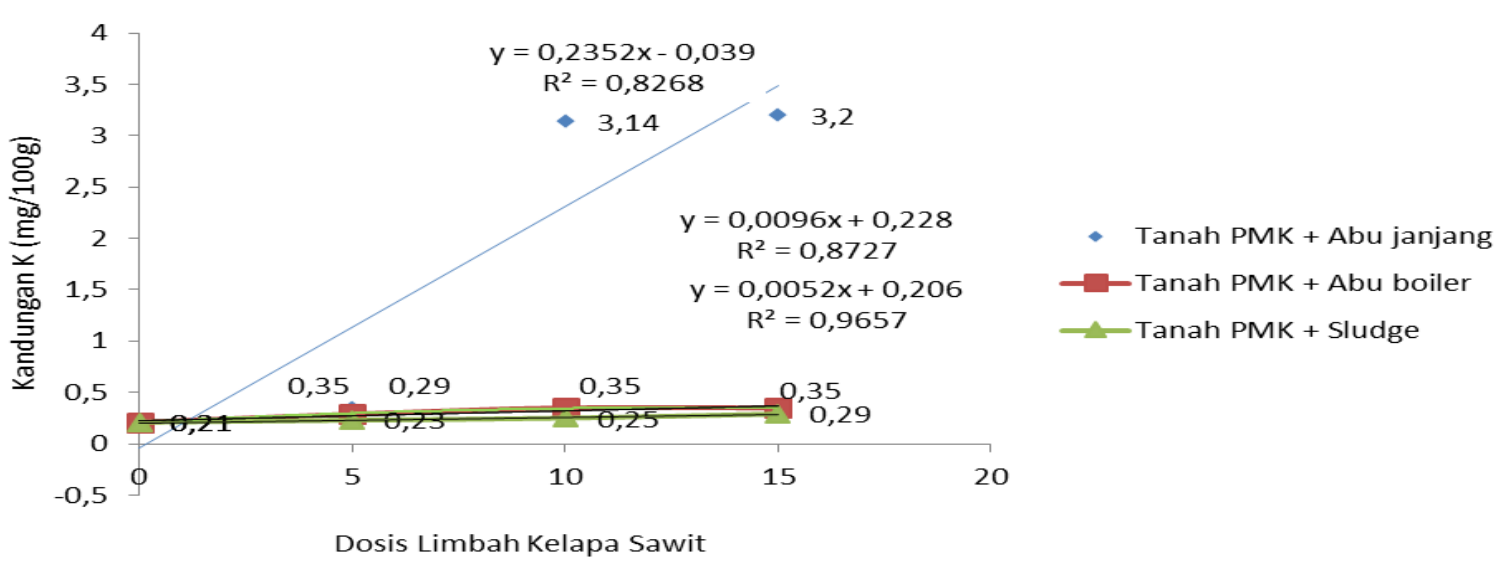

Gambar 4. Grafik respon kandungan hara $\mathrm{K} 2 \mathrm{O}(\mathrm{mg} / 100 \mathrm{~g})$ setelah diinkubasi dengan berbagai limbah kelapa sawit 
Gambar 4 menunjukkan bahwa peningkatan berbagai dosis limbah kelapa sawit memberikan berpengaruh terhadap kadar $\mathrm{K}$ dengan kurva respon linear positif. Abu janjang, abu boiler dan sludge memiliki nilai koefisien determinasi R2 masing masing sebesar 0,826; 0,872 dan 0,965 .

\section{Pembahasan}

Hasil percobaan menunjukkan bahwa perlakuan abu janjang, abu boiler dan sludge kelapa sawit dengan dosis 5, 10 dan 15 ton/ha pada bahan podsolik merah kuning berpengaruh terhadap kadar $\mathrm{pH}, \mathrm{N}, \mathrm{P}$ dan $\mathrm{K}$. Pemberian berbagai jenis limbah kelapa sawit menyebabkan peningkatan kadar $\mathrm{pH}, \mathrm{P}$ dan $\mathrm{K}$, namun menyebabkan penurunan nilai $\mathrm{N}$ total pada jenis abu limbah. Peningkatan kadar hara terbanyak terdapat pada perlakuan abu janjang sawit dosis 15 ton/ha

Pemberian berbagai jenis dan dosis limbah kelapa sawit nyata meningkatkan $\mathrm{pH}$ tanah. Kenaikan $\mathrm{pH}$ pada setiap perlakuan dipengaruhi oleh senyawa K2O dalam abu janjang kelapa sawit. Senyawa tersebut didalam tanah bereaksi dengan $\mathrm{H} 2 \mathrm{O}$ dan menyumbangkan ion $\mathrm{OH}$-. Menurut Panjaitan et al. (2003) senyawa MgO dapat mengusir $\mathrm{Al}$ sehingga $\mathrm{pH}$ tanah PMK akan meningkat. Pada bahan podsolik merah kuning tidak diikuti oleh peningkatan hara $\mathrm{N}$ untuk abu janjang dan abu boiler pada dosis 5,10 dan 15 ton/ha, sehingga terjadi penurunan kadar $\mathrm{N}$-total. Kehilangan $\mathrm{N}$ dari bahan podsolik merah kuning disebabkan karena di dalam tanah mengalami proses nitrifikasi yang meningkatkan potensi pelindian N. Senyawa NO3+ sifatnya sangat mobil, sangat larut air, tidak dapat dipegang oleh koloid tanah. Ketika abu janjang diinkubasi selama 1 bulan dan selama proses inkubasi dilakukan penyiraman mengakibatkan abu janjang akan terurai didalam tanah sehingga kandungan $\mathrm{N}$ tanah akan mudah hilang (Sasli, 2011). Selain itu juga di dalam tanah terjadinya proses immobilisasi atau pengambilan $\mathrm{N}$ anorganik oleh mikroorganisme didalam tanah (Winarso, 2005). Peningkatan terjadi pada pemberian sludge dosis 15 ton/ha disebabkan karena di dalam sludge kandungan $\mathrm{N}$ masih ada karena sludge tidak berasal dari proses pembakaran sehingga perlu penambahan dosis dalam jumlah yang banyak untuk meningkatkan ketersediaan $\mathrm{N}$ didalam tanah.

Pemberian berbagai jenis limbah nyata meningkatkan kadar $\mathrm{P}$ dan $\mathrm{K}$ pada dosis 5,10 dan 15 ton/ha. Peningkatan ini terjadi karena dipengaruhi oleh $\mathrm{pH}$, ion $\mathrm{Fe}, \mathrm{Al}$, dan tingkat dekomposisi bahan organik. $\mathrm{pH}$ tanah yang diinkubasi abu janjang, abu boiler dan sludge mengalami peningkatan, seiring peningkatan $\mathrm{pH}$ sehingga kandungan $\mathrm{Al}-\mathrm{P}$ dan Fe-P dapat terlepas dan menjadi bentuk yang tersedia bagi tanah PMK (Susanto, 2005). Peningkatan K disebabkan karena jumlah kation-kation basa seperti $\mathrm{K}+, \mathrm{Mg} 2+, \mathrm{Ca} 2+$ dan $\mathrm{Na}+$ yang disumbangkan telah terjerap dan mendominasi kompleks jerapan, adanya indikasi bahwa kation-kation basa telah terjerap dan lebih banyak pada koloid tanah dibandingkan dengan $\mathrm{Al3}+$ dan $\mathrm{H}+$ (Mahbub, 2011).

\section{KESIMPULAN DAN SARAN}

\section{Kesimpulan}

Berdasarkan hasil penelitian ini dapat ditarik kesimpulan bahwa hasil analisis sifat kimia tanah PMK dengan penambahan abu janjang, abu boiler dan sludge dosis 5,10 dan 15 ton/ha yang diinkubasi selama satu bulan dapat meningkatkan nilai $\mathrm{pH} \mathrm{H} 2 \mathrm{O}, \mathrm{P}$ dan $\mathrm{K}$ pada tanah PMK, tetapi terjadi penurunan $\mathrm{N}$ total tanah pada perlakuan abu janjang dan abu boiler kecuali pada sludge. Dilihat dari beberapa perlakuan abu janjang, abu boiler dan sludge yang digunakan maka abu janjang dosis 15 ton/ha merupakan bahan terbaik dalam peningkatan $\mathrm{pH} \mathrm{H} 2 \mathrm{O}, \mathrm{P}$ dan $\mathrm{K}$. Sedangkan sludge dosis 15 ton/ha merupakan bahan terbaik dalam peningkatan sifat kimia $\mathrm{N}$ pada tanah PMK.

\section{DAFTAR PUSTAKA}

Baharuddin, A. S., M. Wakisaka., Y. Shiray., S. A. Aziz., N. A. A. Rahman dan M. A. Hasan. 2009. Composting of Empty Fruit Bunch and Partially Treated Palm Oil Mill Effluent in Pilot Scale. International Journal of Agricultural Reasearch, 4 (2): 69-78.

BPS. 2013. Jumlah Perusahaan Besar Menurut Jenis Tanaman $2000 \quad-2013$. http://www.bps.go.id/tab_sub. Diakses tanggal 12 Desember 2014.

Departemen Pertanian. 2006. Pedoman Pengelolaan Limbah Industri Kelapa Sawit. Rineka Cipta. Jakarta.

Ginting, J. 1991. Pemanfaatan Limbah Abu Janjang Kelapa Sawit sebagai Pupuk Kalium pada Pertanaman Kentang di 
Dataran Tinggi Karo. Tesis. Fakultas Pascasarjana Bogor.

Hanibal. Sarman dan Gusniwati. 2001. Pemanfaatan Abu Janjang Kelapa Sawit pada Lahan Kering dan Pengaruhnya Terhadap Pembentukan Nodula Akar Pertumbuhan dan Hasil Tanaman Kedelai (Glaycine max). Skripsi. Fakultas Pertanian Universitas Jambi.

Indrihastuti, D. 2004. Kandungan Kalsium pada Biomassa Tanaman Acacia mangium Willd dan pada Tanah Podsolik Merah Kuning di Hutan Tanaman Industri. Skripsi. Fakultas Kehutanan IPB.

Jenny, M. U dan E. Suwadji. 1999. Pemanfaatan Limbah Minyak Sawit (Sludge) sebagai Pupuk Tanaman dan Media Jamur Kayu. Jurnal Penelitian dan Pengembangan Aplikasi Isotop dan Radiasi. Hal 345-351.

Mahbub, I. A., A. Muzar dan Ermadani. 2011. Pengaruh Residu Kompos Tandan Buah Kelapa Sawit tehadap Beberapa Sifat Kimia Ultisol dan Hasil Kedelai. Jurnal Penelitian Universitas Jambi Seri Sains, 13 (2): $11-18$

Susanto, R. 2005. Dasar-Dasar IImu Tanah. Kanisius. Jakarta. 67 hal.

Tim PT SP. 2000. Poduksi Bersih Pengolahan Tandan Buah Segar di Pabrik Kelapa Sawit (pengalaman PT Salim Indoplantation di Riau). Makalah Lokakarya Pelaksanaan Produksi Bersih pada Industri Minyak Sawit. Pekanbaru, 2-3 Maret 2000.

Winarso, S. 2005. Kesuburan Tanah : Dasar Kesehatan dan Kualitas Tanah. Gava Media. Jogjakarta. 269 hal.

Yamani, A. 2010. Analisis Kadar Hara Makro dalam Tanah pada Tanaman Agroforestri di Desa Tambun Raya Kalimantan Tengah. Jurnal Hutan Tropis, 11 (30): 3746.

Yuliana, E. D. 2012. Jenis Mineral Liat dan Perubahan Sifat Kimia Tanah Akibat Proses Reduksi dan Oksidasi Pada Lingkungan Tanah Sulfat Masam. Jurnal Bumi Lestari, 12(2): 327-337. 
Pemanfaatan Beberapa Jenis dan Dosis Limbah Kelapa Sawit (Fitri Ramadhani, et al) 


\section{$\mathbf{J}$

PERUBAHAN SIFAT KIMIA TANDAN KOSONG KELAPA SAWIT YANG DIFERMENTASI DENGAN EM4 PADA DOSIS DAN LAMA PEMERAMAN YANG BERBEDA

Changes Of Chemical Properties Compost Oil Palm Empty Fruit Bunch Fermented With Em4 Dosage And Long Different Ripening

Abdul Rahman Toiby, Elfi Rahmadani, dan Oksana

PEMANFAATAN BEBERAPA JENIS DAN DOSIS LIMBAH KELAPA SAWIT (Elaeis guinensis Jacq) TERHADAP PERUBAHAN PH, N, P, K TANAH PODSOLIK MERAH KUNING (PMK)

Fitri Ramadhani, Ervina Aryanti, dan Robbana Saragih

UPAYA PENINGKATAN HASIL MENTIMUN SECARA ORGANIK DENGAN SISTEM TASALAMPOT

Increasing the Yields of Cucumber by Tasalampot Organic Farming System

Indah Permanasari dan Aulia Rani Annisava

PERTUMBUHAN BIBIT KELAPA SAWIT (Elaeis guineensis Jacq.) DI PEMBIBITAN UTAMA PADA MEDIUM SUB SOIL ULTISOL YANG DIBERI ASAM HUMAT DAN KOMPOS TANDAN KOSONG KELAPA SAWIT

The Growth of Palm Seedlings (Elaeis guineensis Jacq.) at the Experiment Farm By Using Medium Of Subsoil Ultisol That Was Treated With Humic Acid and Fruitless Palm Bunch Compost

Janrico Valentino Sembiring, Nelvia, dan Arnis En Yulia

INDUKSI KALUS PASAK BUMI (Eurycoma longifolia Jack) MELALUI EKSPLAN DAUN DAN PETIOL

Callus Induction of Eurycoma longifolia Jack by Leaf and Petiole Explant

Rosmaina, Zulfahmi, Probo Sutejo, Ulfiatun, dan Maisupratina

KEPADATAN DAN POLA PENYEBARAN PASAK BUMI (Eurycoma longifolia Jack) DI ZONA ALAMAN KUYANG, HUTAN LARANGAN ADAT KENEGARIAN RUMBIO

Density and Distribution Pattern of Eurycoma longifolia Jack) In The Alaman Kuyang Zone of The Forest Reserve of Kenegarian Rumbio

Zulfahmi, Nelawati, Rosmaina 